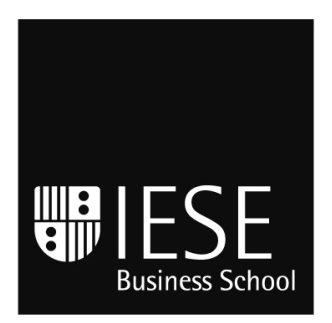

"la Caixa" Chair of Corporate Social

Responsibility and Corporate Governance

Working Paper

WP no 707

September 2007

University of Navarra

\title{
ANTHROPOLOGICAL AND ETHICAL FOUNDATIONS OF ORGANIZATION THEORY
}

\author{
Antonio Argandoña
}

IESE Business School - University of Navarra

Avda. Pearson, 21 - 08034 Barcelona, Spain. Tel.: (+34) 932534200 Fax: (+34) 932534343

Camino del Cerro del Águila, 3 (Ctra. de Castilla, km 5,180) - 28023 Madrid, Spain. Tel.: (+34) 913570809 Fax: (+34) 913572913

Copyright ${ }^{\odot} 2007$ IESE Business School. 


\title{
ANTHROPOLOGICAL AND ETHICAL FOUNDATIONS OF ORGANIZATION THEORY
}

\author{
Antonio Argandoña*
}

\begin{abstract}
The increasingly frequent and forceful criticisms of management sciences suggest that we need a new model. In fact, the number of proposed alternatives has multiplied, with some suggesting that the range of economic points of departure be extended, while others turn to different sciences (sociology, psychology, neuroeconomics, political sciences, philosophy) for their inspiration. This article suggests returning to the origins of economic science, action theory, with a broader approach that takes in the contributions of realist philosophy (Aristotle, Thomas Aquinas) with a view to laying the foundations for a richer organizational theory in which ethics plays a clearer role.
\end{abstract}

* Professor of Economics, IESE

Keywords: action theory, ethics, firm, management, moral virtues, organizational theory. 


\section{ANTHROPOLOGICAL AND ETHICAL FOUNDATIONS OF ORGANIZATION THEORY}

\section{Introduction $^{1}$}

As Kuhn (1962) explained, the progress of science is discontinuous. Over time, the dominant theory becomes consolidated, developing and extending its influence into other areas. However, sooner or later conventional science either cannot explain certain specific cases or its recommendations display unwanted effects. The reaction of academics is to adapt their assumptions to take these exceptions into account, although this eventually complicates the model, robbing it of its initial simplicity and appeal. The critical voices become more numerous and dissatisfaction increases and, there being no clear alternative to the conventional theory, conflicting ideas begin to emerge, the works of ancient thinkers are revisited, and inspiration is sought in other disciplines.

It seems to me that the final years of the $20^{\text {th }}$ century and the first few years of this one have been a time of uncertainty in management theory and in those economic theories that for many years served as its foundations. It will be some years yet before we are able to say with any certainty whether what we are seeing now really is a deep crisis in current management theory or merely the growing pains, though I suspect it is the former. It is not my intention in this article to perform an in-depth analysis of the current model, since other social scientists have already done this effectively enough. ${ }^{2}$ Instead, I want to offer some observations on how we might find a way out of the current crisis, if it indeed exists.

\footnotetext{
1 This article forms part of the work of the "la Caixa" Chair of Corporate Social Responsibility and Corporate Governance, IESE Business School, University of Navarra.

${ }^{2}$ Cf., for example, Donaldson (2002), Ferraro, Pfeffer and Sutton (2005), Ghoshal (2005), Rocha and Ghoshal (2006).
} 
The aim of this article is as follows. First, we will revisit action theory which is essentially the starting point for the current economic model: that economics is a theory of action (Mises, 1949). Managing involves taking certain actions within the context of a human organization. Organization theory should therefore be based on action theory. Conventional economic theory is also a theory of action, but one based on an excessively restrictive anthropology, so we will turn instead to realist philosophy (Aristotle, Thomas Aquinas) in our search for a broader conception of the characteristics of such action, of which economic theory (in its neoclassical form but also in some of its more recent incarnations) will be a specific example.

We will thus be able to refer to more complex assumptions that can be used to explain human action within organizations, and develop a more complex theory of organization that once again treats today's current theories as specific cases. This broader-based anthropology will also allow us to discuss the role of ethics in organization theory, since ethics should not be treated as an added, superimposed element, but rather should originate from the same anthropology. This will lead to a stronger understanding of ethics that will, in turn, result in the natural integration of ethics into organization theory, in such a way that ethics becomes "the condition of stable equilibrium“ (Argandoña, 1985, page 298) for the behavior of individuals, institutions, organizations and firms, as well as economic systems.

My intention in this article is, obviously, not to develop an entirely alternative theory of organization, but instead to indicate some of its initial stages. As MacIntyre (1990) explained, if one wants to change a model, it is not enough just to present an alternative. One must also demonstrate why the new model is better than the old one and, above all, how one can make the transition from one to the other, i.e., how the application of the new model will allow one to solve the same problems that the other model resolved, but without any of its restrictions or unwanted consequences, while at the same time offering a way of tackling new problems, to the extent of changing the research agenda for the discipline in question. This requires an indepth knowledge of both models, something which I do not have. As in some of my earlier works (Argandoña, 2003, 2005, 2007a, 2007b), I have substantially drawn on the work of an IESE Business School colleague, Juan Antonio Pérez-López, who died a few years ago and who broadly explained and demonstrated what I will attempt to show in this article (cf., mainly, Pérez-López, 1991a, 1993b, 1998; also see Rosanas, 2006).

\section{Action Theory}

"Managing consists of leading a company from its current position to a future position that is better in relative terms" (Valero and Lucas, 1991, page 28): leading a human team (managing always means managing people) to change the current situation and obtain results in an efficient way (at least in business organizations). ${ }^{3}$ Management is, first and foremost, action. We must therefore turn to action theory, which has traditionally been the preserve of economic science, as a first step in understanding what people-management consists of.

\footnotetext{
${ }^{3}$ Managing involves other duties, at least for the higher levels of management: analyzing and diagnosing the present in terms of business, management structure, professional co-existence and institutional configuration, selecting and carrying out these duties and selecting and applying procedures that are suitable for the company's governance (Valero and Lucas, 1991, page 27).
} 
Human action is intentional: by acting, a human being tries to achieve some end that he or she has set for himself, and his or her purpose or intention is what gives meaning to the action. ${ }^{4}$ In any action, the agent identifies a less satisfactory situation (a need) and acknowledges the possibility of transforming it into a more satisfactory situation, as well as the desirability of this transformation, which is the action's end, goal or objective. There follows the deliberation, in which the subject identifies the means or resources available, formulates the possible alternatives for achieving the end, analyses the consequences that can be expected from their implementation (that is, he or she formulates a representation of the situation that is expected to prevail after the action has been performed and compares it with the original situation), establishes the criteria under which the means will be appraised, and carries out the appraisal.

Desire is then turned into action, turning the potential motivation (the satisfaction of a need) into an actual motivation to perform the action. Then, the decision is taken (the means to carry out the action are chosen), and the action is performed (an act of will by which the agent sets in motion the means that he or she has chosen: the "transforming efficacy of action").

Then, over time, come the action's consequences or results - how and to what extent the planned end is achieved or other effects are obtained, including effects that were not expected or not desired - the evaluation of the action's consequences in the light of the results attained and the resulting learning for the agent, and, finally, the correction of the decision, if the action is to be repeated in the future or forms part of a broader plan.

In neoclassical economics, the theory of action follows the previous model, but with certain differences that are worth pointing out. The action's end is also the satisfaction of a need felt by the agent, in accordance with a function of preferences which the agent takes as given. The deliberation consists of looking for alternatives (means) and appraising them. This process is usually carried out in terms of the subjective values attributed by the agent to the expected or anticipated results (objective values) of his or her choices, within a plurality of possible states. By inserting all preferences in a single function (utility function or order of preferences), under the assumption that the values are commensurable, it is possible to perform (mental) comparisons between the expected subjective outcomes using a single comparison unit (ordinal), which is the expected utility in each case. This establishes the decision criterion that the agent will use, which is the maximization of his or her utility, in accordance with the "economic principle": the agent always tries to obtain the best result that can be obtained with the limited means available - or, alternatively, the agent always uses the lowest possible quantity of means to obtain a given result. ${ }^{5}$

The motivation for the action is the satisfaction of a need and that alone is sufficient to start the process; no distinction is made between potential and actual motivation. The decision consists of the choice of means for maximizing the expected utility. The economist usually does not consider the execution phase: the fact that the agent is considering the possibility of acting automatically implies the will to act - and the capacity to do so, supposing he has the necessary resources. The action's results are also of little interest to the economist, at least in non-repetitive actions or actions which do not form part of complex plans: the agent makes his

\footnotetext{
${ }^{4}$ The action theory explained here draws its inspiration from Pérez-López (1991a), Pilsner (2006) and Yepes (1996).

${ }^{5}$ Certain hypotheses are added, such as that of continuity (to avoid lexicographic preferences), that of the preferences' internal consistency (to assure the decision's rationality), and that of the preferences' quasi-concavity and the infinite divisibility of goods (to guarantee the existence of a single optimal result when the range of feasible solutions is convex).
} 
decision based on the appraisal (utility) attributed to the action's expected consequences, in accordance with a given, unvarying function of preferences; therefore, the fact that the action's actual consequences do not match its expected consequences cannot influence the decision, which has already been made. In other words, either the agent does not learn from the consequences of the action or such learning is irrelevant because it has no effect on the decision that has already been made. ${ }^{6}$ Therefore, the evaluation of the action's consequences is not relevant either, and neither is the correction of possible future decisions, at least in the case of non-repetitive actions.

As we shall see, these differences indicate where the changes in action theory and organization theory should be introduced.

The most interesting cases in action theory, particularly where this involves action within an organization (and, therefore, management action, though not exclusively) are those in which a person (the "active agent") interacts with another person (the "reactive agent") rather than with a non-human environment. Furthermore, such actions are not isolated from but instead form part of a series of repeated actions or plans, because the active agent (whom we shall assume is the manager) now has a need (she has to make a decision that affects either her or the whole organization), and she knows that this need will recur (she will have to make similar decisions in the future) and that she has many other needs which she may not be feeling here and now but which she will also have to satisfy, now and in the future. This means that to solve a problem the decision-maker must evaluate the action from three points of view: 1) how well it will satisfy the current need; 2) what effects it will have on the agent's ability to satisfy that same need when it recurs in the future; and 3) what effects it will have on the agent's ability to satisfy not only that need, but all her needs, now and in the future.

This means that the agent will have to consider all the (reasonably foreseeable) results of the action, which can fall into three categories: 1) the "extrinsic" result or the reactive agent's response (such as the manager giving an order and the employee complying with that order in such a way that the manager's wishes are satisfied, the manager gains prestige, and so on); 2) the "intrinsic" result or the effects on the active agent, other than the reactive agent's response (for example, what the active agent learns on an operational level or the satisfaction he gets from performing the action: the satisfaction of giving an order and being obeyed, learning about the interaction that occurs or the results of this interaction, etc.); and 3) the "external" result or the effects the action has on the reactive agent (for example, what the reactive agent learns as a result of the action) (Pérez-López, 1991a, page 28). We are clearly looking at a range of results that is broader than that found in conventional economics.

If this is the case, the active agent will have to assess three aspects of his or her decision:

1) The extent to which the action contributes to achieving the specific purpose of the action (what Pérez-López calls the "effectiveness" of the action). The action of giving an order is effective if the reactive agent complies with the order in the way the manager wishes. This corresponds with the result of the decision as analyzed by conventional economics, in terms of a utility function subject to restrictions such as preferences, resource availability, etc.

\footnotetext{
${ }^{6}$ Economic models for human action (and, therefore, those that refer to organizations), with their well-defined utility functions and assumptions of perfect knowledge, work on the premise that agents will not learn and will, therefore, act like machines (Rosanas, 2006, page 16). Given that such learning does indeed exist and is important, these models are insufficient.
} 
2) The satisfaction that the action brings the active agent and the value of the learning brought about by the decision (the "efficiency" of the action), that is, the extent to which the action helps to develop the skills (operational habits) that will make it easier to satisfy those same needs when they recur in the future. The action of giving the order will be efficient if, thanks to this action, the agent learns to give better orders in the future and is also motivated to do so.

3) For the active agent, the value of the learning that takes place in the reactive agent is a result of the experience of the interaction (the "consistency" of the action). The action of giving the order will be consistent if the employee learns to comply better in the future, or is more disposed to comply, or is in a better position to understand the orders received, etc. The active agent must take into account the fact that the interaction with the reactive agent will bring about changes in the reactive agent's behavior that will make future interactions either easier or more difficult and so will affect the active agent's ability to satisfy future needs with that same reactive agent.

Organization theory should, then, be based on an action theory that is not confined to the response of the reactive agent and the satisfaction it gives the active agent; that is, the effectiveness of the action. In the evaluation of the action, the agent must take into account not only the direct effects deriving from the reactive agent's response, as does traditional theory, but at least two other realities:

1) Operational knowledge: what the active agent herself learns about the action. Any analysis of an action is incomplete if it ignores this type of learning, that is, the impact the action has on efficiency. ${ }^{7}$

2) Evaluative knowledge: the ability to recognize other people's inner states; that is, to assess the consistency of an action. An action is consistent if, after the first "transaction" (action-reaction cycle), the other party is more motivated, or at least not less motivated, to engage in a new cycle. Any analysis of an action will be incomplete if this point is omitted. That is so for two reasons:

a) It may be that, as a consequence of the first interaction, the reactive agent becomes less interested in participating in further interactions ("negative learning" occurs). For example, if the manager abuses the employee's confidence in order to achieve the desired end, he is unlikely to be able to obtain that employee's future collaboration.

b) And, depending on the active agent's evaluation of the effects his action has on the reactive agent, the active agent himself will experience changes, and those changes may make it more difficult for him to satisfy other needs and develop beneficial interactions with other agents in the future. Each time a person performs an action that affects other people, there is a personal learning process that provokes changes in the active agent when he takes into account (or ignores) the effects that the action he is about to perform will have on the reactive agent, because those are the changes that explain how the agent actually improves.

\footnotetext{
${ }^{7}$ This type of learning is taken into account in sociology and economics, and is included in some decision theories (cf. Argandoña, 2003, 2005, 2007a, 2007b).
} 
Thus, action theory first offers a dynamic decision theory that considers not only a decision's direct impact (the dimension of effectiveness), but also its other effects (on the planes of efficiency and consistency). This is important for organization theory, because a manager's inconsistent decisions will eventually affect the effectiveness and efficiency of her actions and, therefore, the possibility of achieving the goals set by her organization (as well as her own personal goals).

Secondly, action theory is also the most suitable way of introducing ethics into the decisionmaking process, because "evaluating human acts according to how much they improve the person who performs them is the very substance of ethics" (Pérez-López, 1977a, page 5). ${ }^{8}$ Furthermore, it offers a solid base for ethics, one resting not on abstract rational principles or extrinsic results (consequences), but on the very reality of the decision process. However, I will deal with the role of ethics at a later point, after I have given a brief explanation of the effects that the action theory described above has on organization theory.

\section{Organization Theory}

An organization is "a group of people who coordinate their actions to achieve objectives in which they all have an interest, albeit for different reasons" (Pérez-López, 1993b, page 13), objectives which they would not be able to achieve, or would find it more difficult to achieve, without the combined actions of the group's members (cf. Rosanas, 2006). Organizations therefore exist to achieve certain common aims in a way that is compatible with the "different reasons" of their members, at least as far as the available resources allow. Organization theory must therefore be based on sound action theory. The reasons are the same as were given earlier: actions inside the company change the decision rules of the people who take part in them and therefore also change the organization itself. Thus, the immediate consequences of those actions will not coincide with their long-term results, and an organization must strive not only to achieve immediate results, but above all, to build the capacity to continue to obtain results in the future (and, of course, ensure that the results are the best possible).

There is no need here to enter into the debate concerning the aims of an organization. Whatever these aims may be, managers must achieve them, and to do so they must secure the cooperation of the members of the organization, i.e., the people who possess the human and material resources that the company needs (owners, employees and, to a certain extent, suppliers, customers and other stakeholders as well). For that, the managers must monitor three "state variables", similar to effectiveness, efficiency and consistency on the personal plane (Pérez-López, 1993b):

1) For an organization, "effectiveness" represents the difference between the economic results obtained by providing a service to people (the consumers) and the resources employed, roughly equivalent to the profit obtained.

\footnotetext{
8 The consequences of an action, in each of the three facets mentioned (effectiveness, efficiency and consistency), will occur whether the agent takes them into account in his or her decision or not and regardless of his intentions. Note that this action theory is symmetrical: the problem can (and must) be analyzed from the standpoint of both the principal and the agent (Rosanas, 2006). This means that the three dimensions of the decision that I go on to mention must be analyzed from the perspective of both the company manager and her subordinates, and problems of ineffectiveness, inefficiency and inconsistency may arise on both sides of the relationship.
}

6 - IESE Business School-University of Navarra 
2) The equivalent to efficiency in personal action is appeal or "attractiveness" in an organization. An organization is attractive when it develops skills in its members that increase satisfaction or reduce the cost of doing something that the organization requires of them, i.e., when it develops distinctive abilities which will allow it to learn how to resolve problems more effectively or how to resolve more complex problems, because its members have a better knowledge of the needs to be addressed and are more capable of addressing them.

3) "Unity" in an organization is the concept that equates to consistency in personal action. Unity is achieved when members of an organization identify with the organization and when trust develops among members and between members, the management and the company.

Effectiveness expresses the company's success in managing material resources. It is a necessary condition for the company's survival, but it is not the company's purpose. "The necessary and sufficient condition for an organization to really exist is that there be a group of people who are motivated to belong to that organization, with all that such belonging implies for them. The organization's objectives must be oriented to conserving and increasing those motivations, as otherwise the organization would disintegrate" (Pérez-López, 1981, page 5). In order to achieve this, the organization fulfills at least some of the requirements which motivate people's contribution to the organization, in terms of effectiveness (it does not give rise to costs in excess of revenues) and attractiveness (it is not unpleasant for people who have to contribute to it). Nevertheless, these are necessary conditions which are not, on their own, sufficient, because, as with personal decisions, an organization must also take account of the consequences for attractiveness and unity which could modify the results achieved, probably in the long term.

Effectiveness is therefore a necessity within the company as an economic institution, but achieving it does not guarantee the organization's survival or continuity. Survival depends on unity. And, contrary to what economics literature says on the subject, this is not an economic problem that can be resolved by designing a control system that provides incentives to use the organization's operational capabilities in order to satisfy the needs of its members, because designing any such system "is absolutely impossible if organizational members learn operationally or morally - as a result of their actions within the organization (...). Achieving optimal economic values is not an economic problem; it cannot be solved by manipulating economic variables alone. It depends on psychological and ethical variables. Only if these latter variables were fixed and could not be altered by learning processes (...) could the optimal economic value be achieved through purely economic processes" (Pérez-López, 1987, pp. 12-13).

Maximizing effectiveness (profits) in the "short term" conditional upon there being no learning (i.e., as if the other variables were constant), is possible in theory, but meaningless, because learning will obviously occur, in which case the conditions for maximum effectiveness will no longer be met. Nor is it possible in advance to "maximize in the long term" and anticipate all the learning that will take place, because, although we know that the agents will learn, we do not know what they will learn, how they will learn or how and when their decision rules will change. 


\section{Which Ethics?}

What is this kind of ethics, built on action theory, that we have proposed? If this action theory is based on the realist philosophy of Aristotle and Thomas Aquinas, ethics must be what these writers proposed: virtue ethics, aimed at creating conditions that will allow the agent to develop as a person, i.e., to be in a position not only to make correct decisions in the present (effective) but also, and above all, to make better decisions in the future (efficient and consistent), because "the mechanism that helps people to make decisions that further their own development is the mechanism classically known as moral virtues” (Pérez-López, 1993a, page 7).

This can also be explained in another way. As mentioned above, decision-making is the result of a set of motivations; some spontaneous, others rational. Spontaneous motivations directly demand a decision based on the expected extrinsic results (effectiveness). However, efficiency and consistency considerations may prompt the agent to make rational decisions, which resist the attractiveness of the spontaneous motivations. The role of moral virtues is specifically that of allowing a person to choose "an alternative that will bring her less economic benefit [a less effective alternative] than another, or various others, which she could have chosen instead" (Pérez-López, 1991b, page 6). ${ }^{9}$ Without virtues, it is probable that the attractiveness that immediate recompense holds for the individual in terms of extrinsic results is so strong that she is not able, firstly, to understand that it is preferable to make another decision which, though less effective, may be more efficient and consistent (i.e., offers the expectation of intrinsic and external results that may lead her to change her choice), and secondly, to exert the willpower to overcome the attraction of the extrinsic results. ${ }^{10}$

Virtues are operational habits that are acquired and developed through (deliberate, effortful) repetition of acts aimed at developing them. This process takes place when the agent makes an effort to achieve what is good both for himself and for another person. "The moral virtues must therefore contain those habits that facilitate the performance of actions that are "good" for others, precisely because they are "good" for others (and not because of any other consequences of the action)" (Pérez-López, 1986, page 17). What moral virtues facilitate is not "doing things" but "wanting things", learning to desire what is best for us, that is, developing the quality of the motives behind actions.

I said earlier that a theory of action (and also, therefore, a theory of organization based on this theory of action) should take account of all the consequences of such action, including the effects that this has on the structure, function, motivation and control of the organization. It would appear that virtue ethics does not add anything substantial to these theories of action and organization, but instead merely offers ethical trappings or certain practical recommendations (which, however, are very important in practice).

\footnotetext{
9 "Ethics analyzes the process by which people may develop their ability to perceive reality, the whole of the reality that affects them, not just the small part of reality that attracts them or that they happen to observe at a particular point in time" (Pérez-López, 1993a, page 6). That whole reality includes, as pointed out above, the external results of action (the reactive agent's response to the active agent's action), which are that readily observable and more attractive reality; but it also includes what the agent himself learns and, above all, the results her actions have for others.

${ }^{10}$ In other words, the behavior we are attempting to describe in economics and the management sciences is "intentional" behavior, i.e., "that behavior that is related to the future (perhaps to the long run), by individuals that are willing to sacrifice short-term satisfactions to obtain some results in the long run" (Rosanas, 2007, page 8). Rosanas, citing Elster (1983) distinguishes three types of explanation in science: causal (such as those of the physical sciences), functional (such as those of the biological sciences) and intentional (such as those of the human sciences). Conventional economic models resort to causal explanations.
} 
Nevertheless, the vast majority of human actions cannot be analyzed on the assumption that people are capable of correctly evaluating in advance the results of their actions in the aforementioned three dimensions, as the real value of those actions can only ever be fully known after the fact; that is, when the decision-maker has already experienced all the effects the action has on his satisfaction. Then, the real problem is not making good decisions, but acquiring the abilities (moral virtues) that will make it possible to always make good decisions (Pérez-López, 1993a, pp. 8-9). As mentioned above, if the people who make up the organization, especially the managers, do not have the necessary virtues, they will not be able to: 1) understand the consequences that will result from actions that turn out to be important (this is the "rational" dimension of a decision-maker's virtues); or 2) exercise the self-control required to take the steps necessary to obtain the extrinsic results of an action without endangering the intrinsic and external results, i.e., to ensure that action is effective, efficient and consistent (this is the "virtual" dimension).

Virtues are, in short, what allow people to develop and strengthen their moral growth and increase their capacity to make decisions that are ever more effective, efficient and consistent, thus overcoming the temptation for spontaneous motivation, i.e., agreeable results in the short term. "Every time a person freely chooses something that he knows is better, even though it is less attractive than another thing that is worse, he is training, building up the strength that will free him of any pressure that might deflect him" (Pérez-López, 1977b, page 10). In short: once fully developed, moral virtues create a state in the agent "that makes all interactions possible" (Pérez-López, 1991a, page 85). "Why be ethical? The simple answer is, in order to learn how to build fully-satisfactory relationships with other people. Being ethical means learning to value people as people; it means learning to love" (Pérez-López, 1990, page 187). ${ }^{11}$

In an organization, ethics allows each member to develop her capabilities to carry out the optimal plan, so that if an agent acts accordingly, her actions will be consistent, and she will be in a position to contribute to the organization's optimal plan. Hence, the contribution of ethics to the development of the organization consists essentially of "maximizing the set of feasible interactions" (Pérez-López, 1990, page 181).

Virtue ethics is generally associated with a "good life" or a "fulfilled life". It should therefore be a necessary part of "good management", because this represents part of the "good life" of both manager and company. In other words, a good manager is an ethical manager, a manager with virtues, a manager who tries hard to achieve excellence (Solomon, 1992). "Perfection is achieved through action in both its aspects: internally (the agent himself) and externally (the product or service offered)" (Rodríguez, 1998, page 27). A manager who lacks virtues may obtain excellent financial results in terms of profits or stock value, but he cannot be a "good" manager, even in the technical sense, because he will lack the ability to understand all the consequences of his actions, particularly the consequences relating to attractiveness and unity. This ability does not depend solely on his intellectual capabilities, but also, and above all, on his analytical knowledge; his capacity to know the internal state of other people, this can only be acquired through the practice of the virtues.

\footnotetext{
${ }^{11}$ If this is the case, action theory relies on virtue ethics and does not require other forms such as deontological, consequentialist or dialogical ethics. More specifically, it receives no support from them (Rodríguez, 1998). In particular, there is no point in including ethical criteria that have been imposed from outside the action itself in the decision-making process, in the way that exogenous restrictions are placed on economic decisions. Cf. Argandoña (2006), Zamagni (2006).
} 


\section{Conclusions}

All social sciences are based on an explicit or implicit anthropology. The anthropology on which economics is based (the anthropology of 'homo economicus') was, in its day, a very useful simplification that was suited to many applications, such as explaining the way markets work in a context where a large number of agents establish impersonal relationships in which the motivations and learning that result from human interaction are almost entirely unimportant. However, when this anthropology was applied to organization theory, its limitations became very clear.

It is easier to criticize than to construct, which is why we lack reliable proposals that offer the potential to overcome the limitations of the dominant model. We are also unable to create a broader theory that not only provides a sufficiently good explanation for what the current theory already explains well, and also overcomes the limitations of this theory, while allowing us to tackle new problems, thus creating a new and more promising tool for research.

Nevertheless, this article represents an attempt to do just that. Based on the theories of Juan Antonio Pérez-López, I have tried to show that the extension of action theory, using elements of realist philosophy (mainly Aristotle and Thomas Aquinas), could help revamp the current model. I have also shown how these theories of action and organization can be combined with virtue-centered ethics, inspired by the same writers. Economics is a positive science of human action, while ethics is a normative science of human action. Therefore, economics and ethics should share their model of humankind, even if they then differ in the methodology and scope of their propositions. There can then be a productive exchange between these two sciences.

The various ethical theories usually focus on one of the three anchor points of the theory of action: the agent, the action itself and its consequences (Solomon, 1998). This gives rise to theories based on intention or motivation and on virtues, on duties or rules (deontology) and on consequences (consequentialism). However, our reflections lead us to conclude that an ethical theory must include all of the elements of action; that is, an ethical code that encompasses wellbeing, norms and virtues (Polo, 1996), not by adding recommendations but by developing a comprehensive explanation of what human action is and what its normative consequences are. This is by no means an easy task, given the plurality of viewpoints on ethics, but would no doubt be made easier by a deeper study of human action.

In fact, since human action seeks what is good for humankind, ethics should study those things that are good and are the intended result of this action. Economics assumes that the agent has sufficient knowledge of her preferences and is better qualified than anyone else to act in accordance with her own interests. However, my previous reflections on learning and changes in decision rules suggest that this is not always achieved. This raises the role of ethics as a long-term "equilibrium condition" for the agent and for all human systems (Argandoña, 1985). Ethics has a primarily negative role: do not make immoral decisions because you will deteriorate as a person, you will harm the communities as well as the society to which you belong, and you will limit your opportunities for future action. This is the first role of the ethics of norms: to place limits on human action, insofar as it can lead to negative learning. These are voluntary limits, of course; moral standards may or may not be adhered to, but this does not detract from their normative content. However, ethical standards are above all positive: do, do good, try to do all you can, and do it well - a message that is consistent with the economic viewpoint of human action. To do this, the agent must develop human capabilities for ethicallycorrect action, i.e. virtues, and also their rational component; because virtues enable agents to improve their capacity for analysis, judgment and appraisal. 


\section{References}

Argandoña, A. (1985), “¿Qué es la economía?,” in Argandoña, A., V. Pou, and F. Segura (eds.),

"Enciclopedia Práctica de Economía," Editorial Orbis, Barcelona, vol. 8.

Argandoña, A. (2003), "Preferencias y aprendizajes," in De Computis et Scripturis. Estudios en homenaje a Mario Pifarré Riera, Real Academia de Ciencias Económicas y Financieras, Barcelona.

Argandoña, A. (2005), "La teoría de la acción y la teoría económica”, in Rubio de Urquía, R., E.M. Ureña, and F.F. Muñoz Pérez (eds.), Estudios de teoría económica y antropología, Unión Editorial, Madrid.

Argandoña, A. (2006), "From ethical responsibility to corporate social responsibility," $6^{\text {th }}$ International Symposium on Catholic Social Thought and Management Education, "The Good Company. Catholic Social Thought and Corporate Social Responsibility in Dialogue”, Rome, October 5-7.

Argandoña, A. (2007a), "Economics, ethics and anthropology," in Djelic, M.L. and R. Vranceanu (eds.), Moral Foundations of Management Knowledge, Edward Elgar, Cheltenham, in press.

Argandoña, A. (2007b), "Integrating ethics into action theory and organizational theory," Journal of Business Ethics, forthcoming.

Donaldson, L. (2002), "Damned by Our Own Theories: Contradictions Between Theories and Management Education," Academy of Management Learning and Education, 1 (1), pp, 96-106.

Elster, J. (1983), “Explaining Technical Change”, Cambridge University Press, Cambridge.

Ferraro, F., J. Pfeffer, and R. Sutton (2005), "Economics language and assumptions: How theories may become self-fulfilling," Academy of Management Review, 30 (1), pp. 8-24.

Ghoshal, S. (2005), "Bad management theories are destroying good management practices," Academy of Management Learning and Education, 4 (1), pp. 75-91.

Kuhn, T.S. (1962), “The Structure of Scientific Revolutions" University of Chicago Press, Chicago, IL.

MacIntyre, A. (1990), "Three Rival Versions of Moral Enquiry. Encyclopedia, Genealogy and Tradition," University of Notre Dame Press, Notre Dame, IN.

Mises, L. (1949), “Human Action,” Yale University Press, New Haven, CT.

Pérez-López, J.A. (1977a), “Moral, ética y negocios”, Technical note, IESE, FHN-113, January.

Pérez-López, J.A. (1977b), “Libertad y economía," Technical note, IESE, FHN-117, December. Reproduced in Pérez López (1998), chapter 5.

Pérez-López, J.A. (1981), "Dimensiones de la responsabilidad social en la empresa," Research Paper, IESE, No 49, January. Reprinted as "Dimensiones de la empresa”, in Pérez-López (1997), chapter 1, and as "Dimensiones de la responsabilidad social de la empresa", in Pérez-López (1998), chapter 2.

Pérez-López, J.A. (1986), "Should businessmen behave ethically?", Technical note, IESE, FHN188-E, December. Reprinted as “¿Deben los empresarios y directivos comportarse éticamente?,” in Pérez-López (1998), chapter 7. 
Pérez-López, J.A. (1987), "El desarrollo de la calidad ética de las personas y su influencia en los logros económicos de la empresa," May.

Pérez-López, J.A. (1990), “I am the boss. Why should I be ethical?”, in Enderle, G., B. Almond, and A. Argandoña (eds.), People in Corporations. Ethical Responsibilities and Corporate Effectiveness Kluwer, Dordrecht.

Pérez-López, J.A. (1991a), "Teoría de la acción humana en las organizaciones. La acción personal," Rialp, Madrid.

Pérez-López, J.A. (1991b), "El logro de la eficacia social a través de la libre iniciativa individual," November, in Pastor, A., J.A. Pérez López, and D. Melé, La aportación de la empresa a la sociedad, Folio, Barcelona, chapter 2.

Pérez-López, J.A. (1993a), “Etica y dirección de empresas,” Technical note, IESE, FHN-111, January.

Pérez-López, J.A. (1993b), “Fundamentos de la dirección de empresas,” Rialp, Madrid.

Pérez-López, J.A. (1997), “Liderazgo,” Folio, Barcelona.

Pérez-López, J.A. (1998), “Liderazgo y ética en la dirección de empresas,” Deusto, Bilbao.

Pilsner, J. (2006), "The Specification of Human Actions in St. Thomas Aquinas,"Oxford University Press/Oxford Scholarship Online, Oxford.

Polo, L. (1996), “Etica. Una versión moderna de los temas clásicos,” Unión Editorial, Madrid.

Rocha, H.O. and S. Ghoshal (2006), "Beyond self-interest revisited," Journal of Management Studies, 43 (3), pp. 585-619.

Rodríguez, A. (1998), "Lugar y desarrollo de la ética en la empresa. Una fundamentación antropológica,” mimeograph, IESE.

Rosanas, J.M. (2006), "Beyond economic criteria: a humanistic approach to organizational survival," Working Paper, IESE, No 654, October.

Rosanas, J.M. (2007), “On the methodology of management research,” IESE, Barcelona, April.

Solomon, R.C. (1992), "Ethics and Excellence. Cooperation and Integrity in Business," Oxford University Press, Oxford.

Solomon, R.C. (1998), "Normative ethical theories," in Wilber D.K. (ed.), Economics, Ethics and Public Policy, Rowman and Littlefield, Lanham.

Valero, A. and J.L. Lucas (1991), "Política de empresa. El gobierno de la empresa de negocios," Eunsa, Pamplona.

Yepes, R. (1996), “Fundamentos de Antropología. Un ideal de la excelencia humana,” Eunsa, Pamplona.

Zamagni, S. (2006), "The ethical anchoring of corporate social responsibility and the critique of CSR," $6^{\text {th }}$ International Symposium on Catholic Social Thought and Management Education, "The Good Company. Catholic Social Thought and Corporate Social Responsibility in Dialogue", Rome, October 5-7. 